\title{
Component level study of an actively lubricated LEG Tilting Pad Bearing: Theory and experiment
}

\section{Cerda Varela, Alejandro Javier; Santos, Ilmar Ferreira}

\section{Published in:}

Tribology International

Link to article, DOI:

10.1016/j.triboint.2017.12.024

Publication date:

2018

Document Version

Peer reviewed version

Link back to DTU Orbit

\section{Citation (APA):}

Cerda Varela, A. J., \& Santos, I. F. (2018). Component level study of an actively lubricated LEG Tilting Pad Bearing: Theory and experiment. Tribology International, 120, 115-126.

https://doi.org/10.1016/j.triboint.2017.12.024

\section{General rights}

Copyright and moral rights for the publications made accessible in the public portal are retained by the authors and/or other copyright owners and it is a condition of accessing publications that users recognise and abide by the legal requirements associated with these rights.

- Users may download and print one copy of any publication from the public portal for the purpose of private study or research.

- You may not further distribute the material or use it for any profit-making activity or commercial gain

- You may freely distribute the URL identifying the publication in the public portal 


\title{
Component Level Study of an Actively Lubricated LEG Tilting Pad Bearing: Theory and Experiment
}

\author{
Alejandro Cerda Varela \\ Escuela de Ingeniería Mecánica \\ Pontificia Universidad Católica de Valparaíso \\ Los Carrera 01567, Quilpué, Chile \\ Email: alejandro.cerda@pucv.cl \\ Ilmar Ferreira Santos \\ Department of Mechanical Engineering \\ Technical University of Denmark \\ 2800 Kgs. Lyngby, Denmark \\ E-mail: ifs@mek.dtu.dk
}

\begin{abstract}
This article constitutes the second step in a research effort aiming at evaluating the feasibility of introducing active characteristics into standard leading edge groove (LEG) tilting pad journal bearings. The strategy proposed is to control the LEG inlet flow using a servovalve. This work portrays the first experimental study for the "proof of concept" of this configuration, as well as a comparison with theoretical results. A simplified setup, featuring a rigid rotor supported by a single pad arrangement is the subject of study. The obtained results prove the viability of the proposed active bearing design, validate the available simulation tool and exemplify on a conceptual level the operational benefits from introducing this technology into standard LEG Tilting Pad Bearings.
\end{abstract}

Keywords: experiment, modelling, tilting pad bearing, active

\section{INTRODUCTION}

The requirements arising from the so called 4th industrial revolution call for an expansion of the usual manner in which rotating machinery is designed 
and operated. Following these new trends, it is desirable that machines feature a higher degree of adaptability to new operational conditions, by introducing "smart" characteristics into their design. As such, the conception of new mechatronic machine elements is an alternative to comply with these requirements.

Bearings are key components to determine the steady state and dynamic characteristics of the rotating machinery $[1,2]$. Consequently, by introducing "smart" characteristics into their design, it is feasible to transfer those properties to the whole machine. For high speed and load applications, tilting pad journal bearings are the support elements of choice, due to their improved stability behavior, compared to other oil film bearing designs [3]. Hence, the improvement of their characteristics by means of the introduction of active characteristics would entail an expansion of the operational limits for turbomachinery as a whole.

Within this scope, a number of investigations have been carried out over the years, considering several strategies for achieving an active tilting pad journal bearing design. The introduction of piezoelectric actuators affecting the tilting pad radial position and resulting bearing clearance was introduced in [4]. Linear and rotational actuators acting directly over the tilting pads were studied in $[5,6,7]$. The usage of electromagnetic actuators installed within the tilting pads was explored by [8].

The usage of hydraulic actuation for achieving active properties in tilting pad journal bearings was introduced by Santos in [9]. Two methods were proposed, being the so called active lubrication concept [10] the one that has received more attention and development in terms of follow-up publications. It proposed the usage of servovalve controlled pressurized oil injection into the bearing clearance, by means of nozzles located on the tilting pad surface, in order to generate controllable forces over the supported rotor. Latest developments in this research effort consider theoretical and experimental investigations. A multiphysics theoretical model for this bearing design has been refined over the years $[11,12,13]$, including a ETHD tilting pad bearing model coupled with the effect of the radial oil injection and dynamics of the hydraulic supply system. The theoretical model has been applied to synthetize model-based controllers to alter the dynamics of a flexible rotor setup in [14]. The feasibility of using this active bearing as an excitation source for carrying out operational modal analysis testing in rotating machinery was experimentally studied in [15].

Recently, the application of the active lubrication concept in tilting pad jour- 
nal bearings featuring the leading edge groove lubrication system has been theoretically studied in [16]. Under such configuration, the injection nozzles located in the tilting pad surface are replaced by the leading edge groove, as the method to provide controllable pressurized oil supply to the bearing clearance. The leading edge groove has already been studied in terms of its benefits considering reduced oil consumption and reduced bearing losses, when compared to other lubrication methods [17, 18, 19, 20].

The results obtained from the mathematical model for the proposed active bearing design validated the initial concept. However, the presented results were only of theoretical nature, being their experimental validation the following step to continue the development of this idea. This is the main motivation for the present publication.

This work inherits the knowledge developed in previous investigations related to tilting pad journal bearings under active lubrication regime. In particular, the test rig and experimental methodologies synthetized previously in $[13,21,22,23]$ constitute the foundation on which this work is developed. As such, the main original contributions of this article are twofold. Firstly, it provides the first set of experimental results concerning the application of the active lubrication concept to a LEG Tilting Pad Bearing arrangement. The experimental data thoroughly describes the steady state and dynamic properties of this novel active bearing design. Secondly, a comparison with theoretical results is provided, obtained by means of the theoretical model presented in [16]. Consequently, this article results enable to validate this simulation tool, and to determine its limitations and range of applicability.

The experimental data reported here was obtained in a simplified setup (single pad arrangement, supporting a rigid rotor with vertical degree of freedom), when compared to the real geometry and application of a tilting pad bearing arrangement. Furthermore, the range of applied loads and journal rotational speeds are within the "low" range, when considering industrial applications. In this respect, in [16] the mathematical model in passive configuration (no active LEG included) was already validated against experimental results reported in [24], obtained under operational conditions resembling an industrial application of a passive tilting pad bearing. Therefore, the scope of this study is to prove experimentally the feasibility of transforming the LEG Tilting Pad Bearing into a mechatronic machine element, and to verify the simulation tool available for such system. Considering these objectives, the simplified test rig setup is sufficient and convenient for a "proof of concept" test campaign, as it reduces the amount of variables that can introduce errors 
in the experimental results. Based on the results presented here, one can determine the viability of testing the proposed active bearing design in a more complex test facility, resembling in a closer manner an industrial application.

\section{EXPERIMENTAL SETUP}

\subsection{Test Facilities}

The experimental results reported in this article were obtained at the Laboratory of Mechatronic Machine Elements at the Technical University of Denmark (DTU). The experiments were conducted using the test facilities depicted in Figure 1. A list of the parameters that describe the setup are provided in Table 1. It consists of a rigid rotor supported in the vertical direction by a tilting pad bearing arrangement. The rotor is attached to a tilting arm by means of roller bearings. The arm constrains the rotor to move solely in the vertical direction. The rotor horizontal movement is restricted by the arm, which is pivoted in one end by a rigid shaft and preloaded angular contact bearings. The driving torque for the rotor is supplied by an electric motor and a belt transmission.

The tilting pad setup used for the test plan is shown in Figure 2. A single pad, featuring the leading edge groove lubrication system and a rocker pivot design, provides vertical support for the rigid rotor mounted on the tilting arm. The oil supply for the leading edge groove (LEG) is provided by a hydraulic hose connected to a high pressure pump and high response servovalve (see Table 1 for details). The bearing chamber is open, and the oil evacuation takes place due to gravity. The servovalve enables to regulate the oil flow towards the LEG using a electrical signal generated in a control unit, introducing active characteristics to the tilting pad arrangement.

The test rig is instrumented to characterize the behavior of the rotor, tilting pad bearing and associated hydraulic supply system. The rotor vertical movement is sensed by means of displacement probes, measuring at the free end and at the midspan of the tilting arm. Different load cells arrangements can characterize excitation forces and oil film forces over the rotor, and they will be described in the following subsection. The LEG is instrumented with a measurement probe, which provides both oil temperature and pressure readout. An additional temperature probe is located at the tilting pad trailing edge center point. Concerning the hydraulic supply system, the servovalve provides a voltage readout of its spool position. Furthermore, a flow meter 
installed between the servovalve and the LEG characterizes the tilting pad oil supply flow.
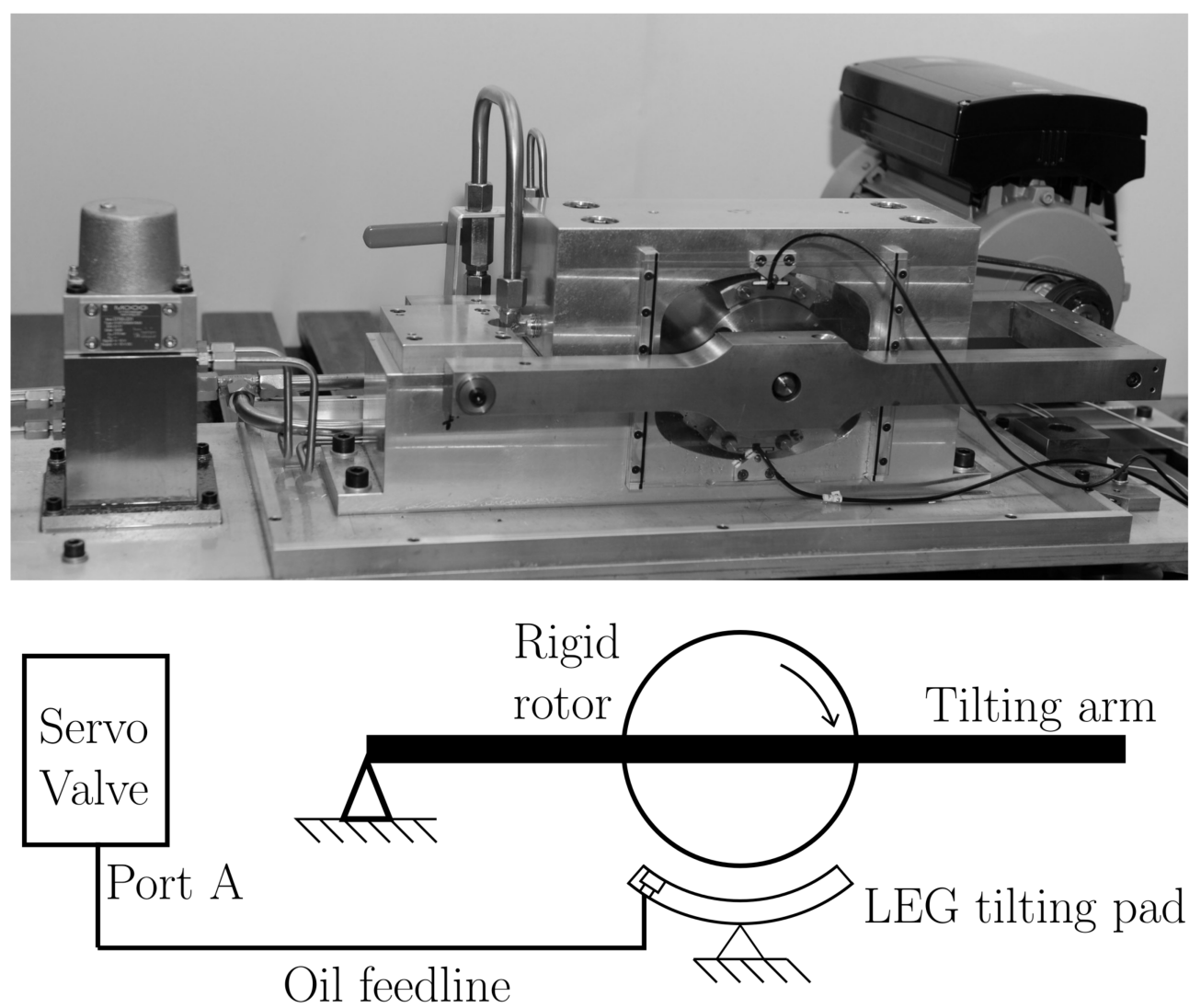

Figure 1: Component level testing of the Actively Lubricated LEG Tilting Pad Bearing: picture and schematics depicting the main components of the experimental setup. Only the bottom tilting pad was retained for the experimental study reported in this article. 

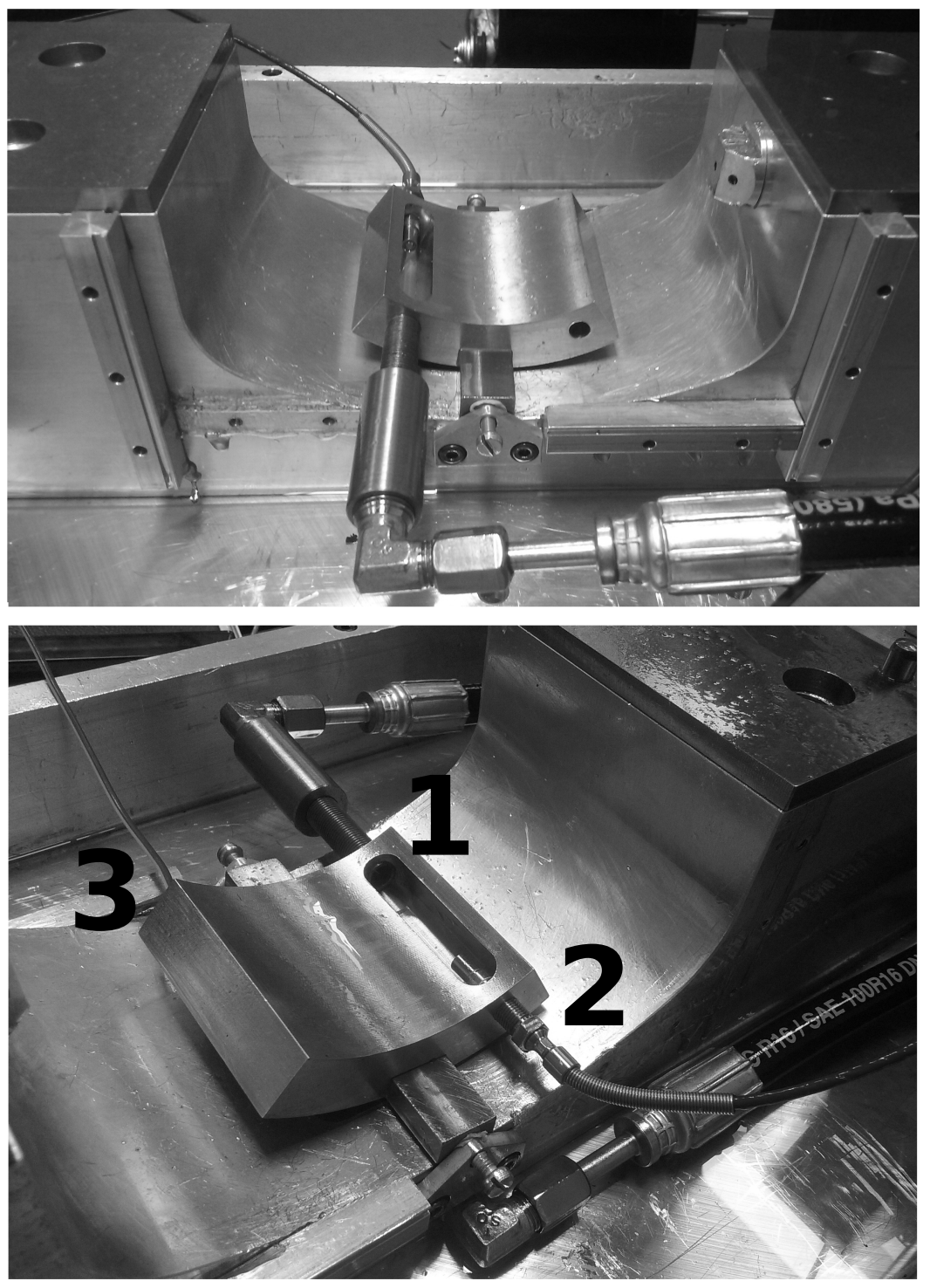

Figure 2: LEG tilting pad used during the experimental campaign: a hydraulic hose (1) connects the leading edge groove to the servovalve output port, in order to provide controllable pressurized flow. A piezoelectric sensor (2) measures the oil pressure within the LEG cavity. Two oil temperature measurement points are set up: one in the leading edge groove cavity (2), and another one (3) located in the tilting pad trailing edge center point 
Table 1: Test Rig Parameters

\begin{tabular}{cc} 
Parameter & Value \\
\hline Pad inner radius & $49.920 \mathrm{~mm}$ \\
Journal radius & $49.692 \mathrm{~mm}$ \\
Bearing axial direction length & $60 \mathrm{~mm}$ \\
LEG axial length & $50 \mathrm{~mm}$ \\
LEG angular position (measured from pad edge) & 5 degrees \\
LEG circumferential direction width & $10 \mathrm{~mm}$ \\
LEG depth & $12 \mathrm{~mm}$ \\
Number of pads & 1 \\
Pad arc & 70 degrees \\
Offset & 0.5 \\
Load Angle & On pad \\
Pad thickness & $16 \mathrm{~mm}$ \\
Oil type & ISO VG22 \\
Pad material & Brass \\
Pivot insert material & Steel \\
Pivot design & Rocker \\
Oil Supply Pump Maximum Pressure & $250 \mathrm{bar}$ \\
Oil Supply Pump Maximum Flow & 2.5 liters per minute \\
Servovalve cut-off frequency $\omega_{V}$ & $150 \mathrm{~Hz}$ \\
Servovalve leakage flow $q_{V}^{*}$ & Variable \\
Servovalve flow pressure coeff. $K_{p q}$ & $1 \mathrm{e}-12 \mathrm{~m} /(\mathrm{sPa})$ \\
Servovalve flow voltage coeff. $R_{V}$ & Variable \\
Servovalve damping ratio $\xi_{V}$ & 0.95
\end{tabular}

\subsection{Test Rig Configurations}

The test rig allows different configurations, aimed at characterizing the static and dynamic behavior of the Actively Lubricated LEG Tilting Pad Bearing. Two arrangements were employed for the experimental study, and can be described as follows:

1. Configuration 1 (see Figure 3): an adjustment bolt is installed at the tilting arm end, in order to constrain its vertical movement. Consequently, it is possible to fix the rotor vertical position to a prescribed eccentricity. The adjustment bolt arrangement includes a load cell, 
which enables to measure indirectly the resulting vertical force generated on the rotor by the bearing oil film pressure field. For this, it is necessary to ensure that no relevant flexible dynamics from the tilting arm are taking place in the studied frequency range. This configuration enables to characterize the steady state characteristics of the tested bearing, as well as the active forces generated when a time varying electrical signal is fed into the servovalve.

2. Configuration 2 (see Figure 4): a set of loading springs enables to apply a vertical load at the tilting arm free end, which is measured by a load cell. Hence, a static load is exerted over the pad. An electromagnetic shaker enables to apply a dynamic excitation force over the tilting arm. This configuration can be used to characterize the dynamic behaviour of the active bearing arrangement via experimentally obtained frequency response functions, where the input is the shaker dynamic force and the output is the tilting arm and rotor vertical movement. Such experiments can be postprocessed to obtain the bearing equivalent stiffness $k_{A L E G}$ and damping $d_{A L E G}$ coefficients. Following the identification method established in [23], by measuring experimentally the frequency response function $F R F(\omega)$ between excitation force $f$ and resulting displacement $y$ at the tilting arm free end, the equivalent frequency dependent dynamic coefficients can be obtained as a function of the excitation frequency $\omega$ as follows:

$$
\begin{array}{r}
k_{A L E G}(\omega)=\operatorname{real}\left(F R F(\omega)^{-1}\right)\left(\frac{l_{2}}{l_{1}}\right)^{2}+\frac{I}{l_{1}^{2}} \omega^{2} \\
d_{A L E G}(\omega)=\operatorname{imag}\left(F R F(\omega)^{-1}\right)\left(\frac{l_{2}}{l_{1}}\right)^{2} \frac{1}{\omega}
\end{array}
$$

Where I is the equivalent inertia of the rotor-tilting arm arrangement with respect to the arm pivot point, $l_{1}$ and $l_{2}$ are defined in Figure 4. For ensuring the effectiveness of this method, all baseline effects coming from the test rig (friction at the arm pivot bearings, static deflection of the arm) must be removed from the experimental results. Furthermore, the method is obtained by modelling the tilting arm as a pivoted rigid body, hence it is only valid in the frequency range where there is no participation from flexible modes of the tilting arm arrangement. 


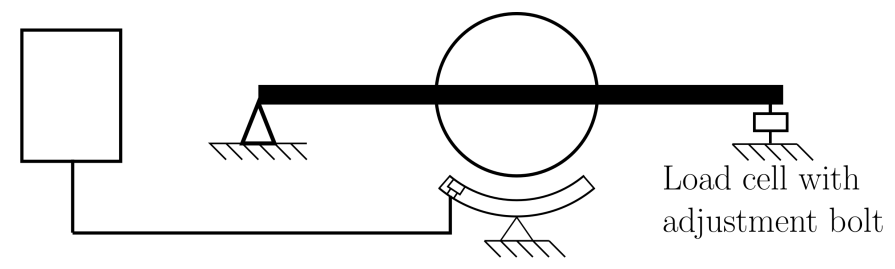

Figure 3: Schematics of the configuration 1 for the test rig

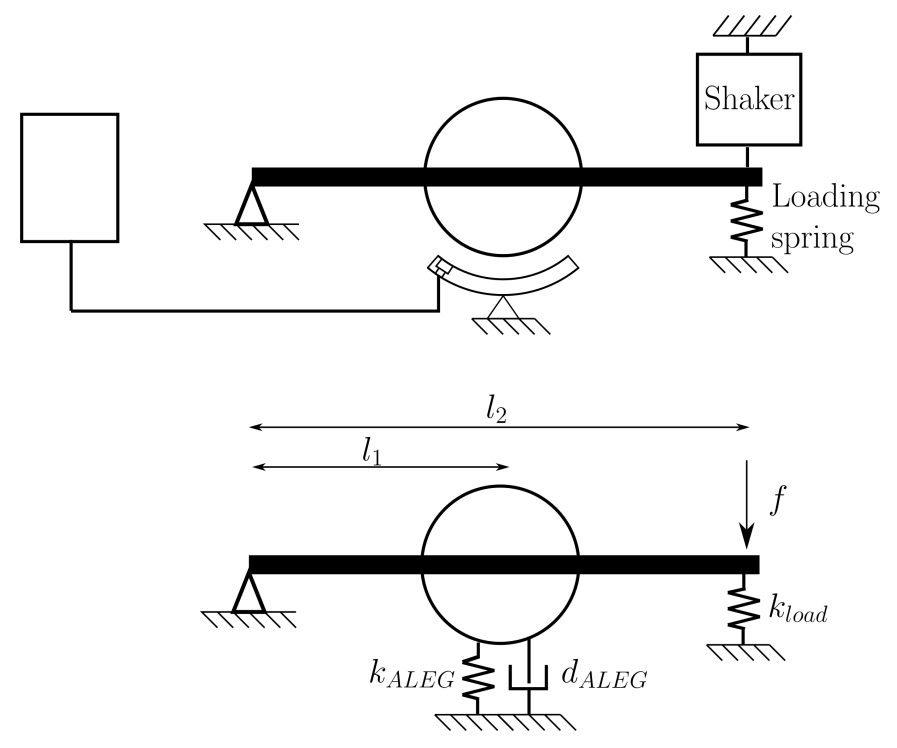

Figure 4: Schematics of the configuration 2 for the test rig

\section{MATHEMATICAL MODEL: ACTIVE LEG BEARING}

The mathematical model for the Actively Lubricated LEG Tilting Pad Bearing was thoroughly formulated and presented in [16]. A detailed description of it is outside the scope of the current article, hence the reader is advised to refer to the provided reference for a complete discussion.

See Figure 5 for a schematics of the relevant nomenclature used in the current article. The domains under study are: hydraulic supply system (servovalve, oil feedline), leading edge groove cavity, oil film, tilting pad and rigid rotor. The hydraulic supply system is modelled by means of a lumped parameter approach, considering linearized behavior for the servovalve actuation. The 


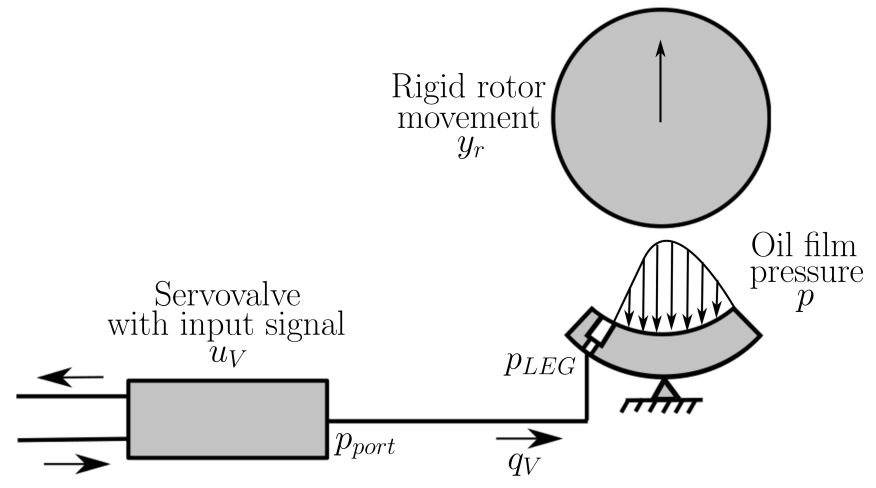

Figure 5: Nomenclature used for the Actively Lubricated LEG Tilting Pad Bearing mathematical model

leading edge groove cavity and its interaction with the oil film domain is represented by means of a mass conservation equation. The oil film is modelled considering a thermoelastohydrodynamic lubrication regime (Reynolds Equation coupled with Energy Equation and Fourier Law for pad heat conduction). The tilting pad is modelled following a pseudo modal reduction scheme, including rigid body motion due to tilting action and pivot flexibility, as well as flexible dynamics due to its first bending mode. The rigid rotor is modelled using Newton Second Law, under the influence of externally applied load and the oil film pressure field resulting force.

The partial differential equations included in the oil film thermoelastohydrodynamic model and the pad flexibility model are solved via the finite element method. Figure 6 depicts the mesh used to discretize the numerical solution of the partial differential equations for the oil film domain. Second order quadrilateral elements compose the mesh. The number of elements for the discretization is deemed sufficient, in the light of the comparison with experimental results, as it can be seen in later sections of this article.

The model is implemented as a computational program in FORTRAN 95. Three types of results can be obtained: steady state position and temperature field via Newton Raphson scheme, equivalent stiffness and damping matrices obtained via perturbation analysis, and time series analysis following a Runge - Kutta - Fehlberg fourth order method with an error estimation step. 


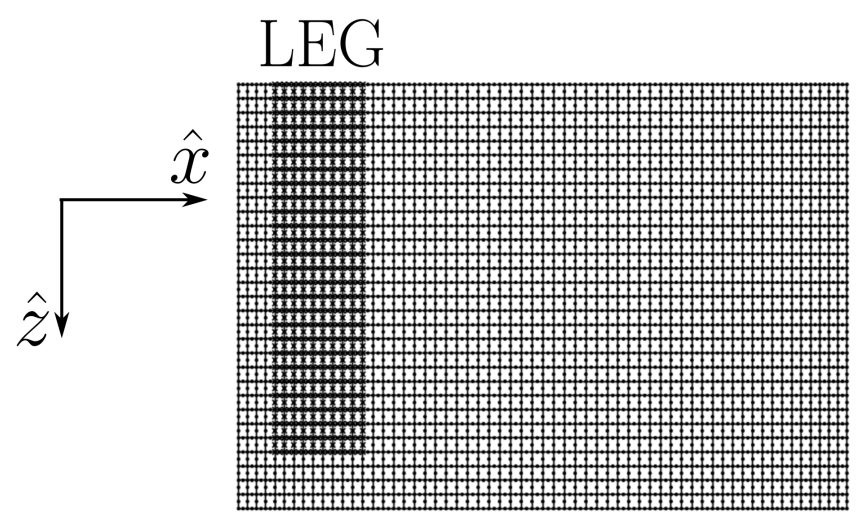

Figure 6: Finite element mesh used for the discretization of the oil film domain in the circumferential (60 elements) and axial (30 elements) direction. The nodes corresponding to the LEG cavity domain are highlighted. Assuming axial symmetry, only half of the pad is modelled. The thermal model and pad flexibility mesh corresponds to the extrusion of this mesh (15 elements in the radial direction)

\section{EXPERIMENTAL AND THEORETICAL CHARACTERIZA- TION OF THE ACTIVE LEG BEARING}

This section aims at characterizing the behavior of the Actively Lubricated LEG Tilting Pad Journal Bearing (named Active LEG Bearing in the following discussion). Results include steady state properties, active force measurement in quasistatic and dynamic operation, and equivalent dynamic coefficients.

The experimental test results are compared with the ones delivered by the mathematical model presented in [16], in order to portray its capabilities concerning the accurate prediction of the static and dynamic characteristics of the Active LEG Bearing.

\subsection{Steady State Characterization}

This set of results were obtained with the test rig operating in configuration 1 . The test cases are listed in Table 2. The experiments were carried out by fixing the journal rotational speed to the reported value. The tilting arm adjustment bolt and load cell were used to adjust the rotor eccentricity, until the required bearing load was obtained. The servovalve control signal was used to regulate the LEG supply flow $q_{V}$, until the flowmeter installed 
Table 2: Test cases for the steady state characterization section.

\begin{tabular}{c|c|c} 
Case \# & Pad Load & LEG Supply Flow $q_{V}$ \\
\hline \hline 1 & $1000 N$ & 1.0 LPM \\
2 & $1000 N$ & $2.0 L P M$ \\
3 & $1000 N$ & $2.5 L P M$ \\
\hline 4 & $2500 N$ & $1.0 L P M$ \\
5 & $2500 N$ & $2.0 L P M$ \\
6 & $2500 N$ & $2.5 L P M$ \\
\hline 7 & $5000 N$ & $1.0 L P M$ \\
8 & $5000 N$ & $2.0 L P M$ \\
9 & $5000 N$ & $2.5 L P M$
\end{tabular}

in the oil feedline measured the value required for each test case. Lastly, the test rig was run under these conditions until thermal steady state was achieved. After a number of preliminary runs, a total of three samples for each test case were obtained. The reported experimental results correspond to their average. Good repeatibility between samples was observed, hence the average is considered a good indicator.

For the mathematical model, the following parameters were imposed according to the experimental values: rotor externally applied load and rotational speed, LEG oil inlet temperature, LEG input flow, rocker pivot stiffness. The results obtained from the model and the experiments under steady state conditions are: rotor vertical equilibrium position $y_{r}$, oil pressure within the LEG cavity $p_{L E G}$, oil temperature at the pad trailing edge center point $T_{\text {out }}$. The results for each test case are reported in Figure 7 for 1000 RPM, 2000 RPM, 3000 RPM respectively.

In general, good correspondence between theory and experiment is observed for the studied parameters. Slightly poorer performance is observed for the prediction of oil exit temperature, specially for higher load and higher rotational speed conditions. Since the LEG input flow was imposed both for the experimental setup and the theoretical model, these results do not verify the soundness of the lumped parameter model for the hydraulic system, and they are restricted to confirm the validity of the constitutive equations of the LEG tilting pad domain (Mass conservation at the LEG, Reynolds Equation Model, Pad Flexibility Model, Thermal Model). 
Besides exhibiting the trivial relationships observed for a tilting pad arrangement (applied load and rotational speed versus rotor eccentricity and oil exit temperature), the results enable to study the relationship between LEG input flow, and the rest of the studied parameters. In general, higher LEG input flow entails higher oil pressure in that cavity. Furthermore, conditions that yield lower "exit" flows through the LEG boundaries also entail an increase of the pressure. For higher applied load over the pad, the LEG pressure tends to increase due to the "higher opposition" to the oil flow at the LEG trailing edge due to increased Pouseuille flow. For higher rotational speeds, the increased Couette flow at the LEG trailing edge yield lower LEG pressure due to the "lower opposition" to the oil exiting the cavity.

The observed correspondence between theory and experiment for the pressure value at the LEG cavity $p_{L E G}$ was only obtained after neglecting the Couette term for the mass conservation equation at the LEG leading edge. This modification of the theoretical model was introduced after observing that a clearly observable amount of oil was leaving the bearing clearance at the pad leading edge, opposing the journal tangential speed direction. From this observation, it could be inferred that the pressure driven flow (Pouseuille term) became dominant on the bearing land between the pad leading edge and the LEG leading edge. Since the oil supply for the bearing was only provided via the LEG, there was not enough oil at the pad leading edge in order to establish the Couette flow in that bearing section. The question arises whether this flow could become relevant in a multi-pad LEG bearing arrangement, where part of the output flow from the previous pad could stay at the journal surface and feed the next pad leading edge.

Concerning rotor vertical position, an accurate characterization of the pivot stiffness and its variation with the load applied on the bearing was critical to properly track the experimental results. In the case of the oil temperature at the pad trailing edge, it can be observed that the theoretical model tends to underestimate its value for higher loads and rotational speeds. According to the theoretical model results concerning oil film pressure field, the tested tilting pad exhibits a cavitated area towards its trailing edge for those conditions. The model includes a rudimentary cavitation model for the pressure field (Gumbell), and no special analysis of cavitation condition is included in the thermal model. Despite this fact, the prediction of the viscosity reduction effect due to temperature build up seems to be accurate enough to provide a good prediction for the rotor equilibrium position.

It can also be noted that, for the same bearing applied load, an increment 
of the LEG input flow yields slightly lower rotor eccentricity. This result implies that by rising the input flow, the increment of the LEG pressure also entails higher pressure within the oil film. Consequently, the modification of the LEG inlet flow via the servovalve input signal $u_{V}$ yields a variation of the oil film resulting force over the rotor, opening the possibility of operating the bearing as a calibrated actuator. This alternative is further explored in the following section.

\subsection{Active LEG Bearing Force Characterization}

In this section, the feasibility of employing the Active LEG Bearing as a calibrated actuator is studied by theoretical and experimental means. The bearing capabilities in this regard are analyzed by the characterization of its "active force", which corresponds to the modification of the force exerted over the rotor by the oil film via an input signal $u_{V}$ fed into the servovalve. Two modes of operation are studied: quasistatic ("slow", step wise modification of $u_{V}$ ) and dynamic ("fast" modification of $u_{V}$, in the form of a chirp signal). In both cases, the test rig was run in configuration 1 . The journal rotational speed and mean vertical load over the pad were fixed. Afterwards, $u_{V}$ was modified following a stepwise or sinusoidal pattern, depending on the operation mode tested. Similar conditions were applied when simulating the experiments with the mathematical model. The measured quantities were: LEG inlet flow $q_{V}$, LEG pressure $p_{L E G}$ and resulting vertical force over the rotor.

\subsubsection{Quasistatic Operation}

Figures 8 and 9 depict the comparison between theory and experiment for the studied bearing active force and LEG pressure, when a stepwise variation of the servovalve control signal is enforced. The studied range for $u_{V}$ varied from $1.5 \mathrm{~V}$ (servovalve fully open) to $0 \mathrm{~V}$ (servovalve closed, only leakage flow is observed), with increments/decrements of $0.1 \mathrm{~V}$. The experiment was performed for two different values of the journal rotational speed and bearing mean load. The stepwise variation of $u_{V}$ was applied over the course of two minutes, registering both the descending and the ascending part of the variation. Two runs were executed for each operational condition.

The experimental results reveal that the measured magnitudes (rotor vertical force and LEG pressure) exhibit linear dependency with $u_{V}$ in the vicinities of the $0 \mathrm{~V}$ point (servovalve closed). The $u_{V}$ voltage range where the linear 
behavior becomes dominant depends on bearing mean load and journal rotational speed. For higher values of $u_{V}$ the bearing response in terms of active force and LEG pressure tends to saturate (converge to a constant value), indicating that the servovalve has fully opened and the LEG input flow has reached its maximum possible value (2.5 LPM), as determined by the available supply pump.

It can be observed that the modification of the active bearing force with the input signal $u_{V}$ becomes stronger for lower bearing mean loads. For such conditions, the oil film pressure diminishes, and so does its resulting moment around the pad tilting point. Consequently, the modification of the LEG pressure due to the signal $u_{V}$ and resulting servovalve flow has a larger impact on the tilting pad equilibrium position and equivalent load over the rotor. In order to increase the active force obtained when a higher mean load is applied over the bearing, a supply pump with larger flow capability should be available.

In general terms, the mathematical model is able to reproduce in a good manner the experimental results, as long as we stay within the observed "linear" range of actuation for the active bearing. This is a consequence of the linearized modelling strategy for the hydraulic system. For obtaining the theoretical results, it was critical to determine experimentally the leakage flow $q_{V}^{*}$ (observed for $u_{V}=0 \mathrm{~V}$ ) and the servovalve flow voltage coefficient $R_{V}$. Both of these parameters exhibit dependency on the journal rotational speed and bearing mean load. The leakage flow varied between 0.8 and 1.3 liters per minute, whereas the servovalve flow voltage coefficient fluctuated between 1.5 and $2.5[L P M / V]$ for the tested conditions.

The dependance of these parameters with the bearing operational condition is consequence of the modification of the pressure value within the oil film and hydraulic supply system, as measured by the LEG pressure probe. As a result, the servovalve behavior is altered due to the modification of its pilot pressure, modifying both its linearized coefficients and leakage flow. This fact adds additional complexities to the practical application of the mathematical model. In this regard, the benefits from the hydraulic linearized modelling strategy in terms of implementation ease come at the cost of higher workload related to the experimental identification of the parameters required for its usage. 


\subsubsection{Dynamic Operation}

The interest here is to study the behavior of the bearing active force when a fast varying $u_{V}$ input signal is imposed. The idea is to exploit the high response capabilities of the servovalve, in terms of fast modifications for the LEG inlet flow. For these experiments, the time depending input signal $u_{V}$ was composed of a mean value of $0.25 \mathrm{~V}$, and a superimposed chirp signal of amplitude $0.1 \mathrm{~V}$, varying its frequency from $1 \mathrm{~Hz}$ to $200 \mathrm{~Hz}$. Such definition for $u_{V}$ ensure that its value is always greater than zero, ensuring that no oil starvation takes place within the bearing. The measured magnitudes are servovalve spool position, LEG pressure and resulting rotor vertical force. The experimental results are postprocessed to obtain frequency response functions, portraying the input/output relationships in terms of magnitude and phase (time delay) as a function of input signal frequency. Only the results with a coherence value greater or equal to 0.85 are kept for the plots.

Figure 10 compares the transfer functions for the servovalve spool, LEG pressure and rotor vertical force with respect to servovalve input signal $u_{V}$. For comparison purposes, the magnitude of each transfer function has been normalized with their respective "zero frequency" value. It can be observed that, for an input signal with low frequency, the behavior of the LEG pressure and rotor vertical force in terms of magnitude exhibits weak frequency dependency, following the trend established by the servovalve spool response (flat response over the studied frequency range). For higher frequencies, it can be seen that the obtained force over the rotor tends to diminish above the servovalve cut-off frequency (marked by the 90 degrees phase lag in the servovalve spool response). In terms of phase lag (time delay), the differences between the three transfer functions are far more relevant in terms of their frequency dependency. From these results, it becomes clear that the phase lag between input signal $u_{V}$ and servovalve spool, LEG pressure and rotor vertical force, as well as between them, is not negligible. Such behavior is a consequence of the dynamics taking place at the level of the servovalve, the hydraulic system and the tilting pad. Consequently, the effort put in introducing these effects into the mathematical model is justified.

Figure 11 depicts the transfer function between servovalve input signal $u_{V}$ and resulting vertical rotor force for two different rotational speeds and three mean bearing loads. These calibration functions show that the Active LEG Bearing can be used as a calibrated actuator, to generate active forces over a wide frequency range. It can be seen that the rotational speed applies a weak 
influence over the magnitude of the calibration functions, whereas the bearing mean load as a stronger impact. These results follows the trend from the quasistatic results, in the sense that higher bearing mean load entails lower magnitude of the obtained bearing active force, for the same servovalve input signal $u_{V}$.

Regarding the frequency dependency of the calibration function, it can be seen that the rotational speed affects it notoriously. Such effect is an artifact of the modification of the pad dynamic behavior due to the oil film equivalent stiffness and damping. The modification of such properties modify the amount of active force that can be obtained at different frequencies for an input signal of the same magnitude. Concerning phase lag between input servovalve and resulting force over the rotor, it can be observed that it exhibits weak dependency with respect to the journal rotational speed and bearing mean load.

Regarding the magnitude of the calibration functions, i.e. the amount of active force that can be obtained per $1 \mathrm{~V}$ of signal fed into the servovalve at different frequencies, the results must be analyzed with care. When calculating the frequency response functions, linear behavior is implicitly assumed. Hence, the magnitude in $[N / V]$ shown here does not take into account non linearities due to actuator saturation, and they are only valid to represent the linear range of the actuator, as described before in subsection "Quasistatic Operation". In other words, the input signal $u_{V}$ must be kept to "low values" in order to use the calibration gains that can obtained in Figure 11.

\subsection{Active LEG Bearing Equivalent Dynamic Coefficients}

The last results related to the characterization of the Active LEG Bearing concern its equivalent stiffness and damping coefficients. The effect of the oil film pressure field over the supported rotor can be represented by linearizing its resulting force, in terms of an equivalent spring and damper. The mathematical model developed for the Active LEG Bearing performs perturbation analysis around the steady state position of the system, delivering dynamic coefficients in the form of frequency independant stiffness and damping matrices. Such matrices feature the dynamic effects arising from the rotor, the pads and the hydraulic model, including their degrees of freedom into their formulation. The full matrices can be dynamically condensed to retain only the rotor degrees of freedoms, if a common condensation frequency is assumed. Therefore, frequency dependant reduced dynamic coefficients are 
obtained. Further details are provided in [16].

Here, experimental and theoretical results for the Active LEG Bearing reduced stiffness and damping coefficients are presented. The experimental results were obtained following the identification method presented before (see Equation 2 and [23] for a in-depth presentation). For obtaining them, the test rig was setup in configuration 2 . Two different values for the journal rotational speed and bearing applied load were established for the study. Regarding the servovalve input signal $u_{V}$, the testing plan covered five different voltage values were imposed. Two data sets were obtained. The results reported here are representative of the observed behavior regarding the influence of servovalve input signal over the bearing equivalent stiffness and damping, with $u_{V}=1 \mathrm{~V}$ and $u_{V}=0.1 \mathrm{~V}$.

Figure 12 and 13 depict the obtained data. The presented results show good coherence between experiment and theory. For obtaining the theoretical results, an accurate characterization of the pivot flexibility and the servovalve flow voltage coefficient $R_{V}$ was fundamental. In general, the frequency dependency for the experimentally identified coefficients follows the trend observed in the theoretical results, with deviations arising from unmodelled dynamics contaminating the identification algoritm results. Such unmodelled dynamics stem from the tilting arm torsional modes in the studied frequency range, which are not accounted for in the identification method.

For all tested cases, it can be seen that by incrementing the servovalve input signal the equivalent stiffness tend to diminish, whereas an increment of the equivalent damping is obtained. This is a consequence of the modification of the equilibrium position of the rotor and pad when the LEG inlet flow is incremented. However, only a modest modification of the equivalent dynamic coefficients is observed. Hence, the usage of constant valued servovalve signals is ruled out as an effective method for altering the system dynamics, at least for the studied setup. The theoretical results presented in [23] proved that higher LEG supply flows (and resulting LEG pressures) could entail stronger modification of the dynamic coefficients.

\section{EXAMPLES OF APPLICATION SCOPE OF THE ACTIVE LEG BEARING}

The previous section has portrayed a experimental and theoretical characterization of the Active LEG Bearing. The results enabled to analyze the 
effect of the servovalve controlled LEG inlet flow over the bearing performance, namely steady state properties, active force and equivalent dynamic coefficients. In general, good agreement between theory and experiment was achieved.

In the following discussion, the focus will be set in presenting the operational benefits arising from the introduction of the active lubrication technology into a LEG Tilting Pad Journal Bearing. It has already been proven, by theoretical and experimental means, that the Active LEG Bearing is capable of generating controllable forces over the rotor in a wide frequency range. Hence, it could be possible to obtain benefits from such capabilities.

Two possible strategies for applying this technology in an operational scenario are portrayed: firstly, the usage of the Active LEG Bearing in open loop configuration, aiming at exciting the rotor to characterize its dynamic behavior during its normal operation, in a non invasive manner. Secondly, the closed loop operation of the Active LEG Bearing, with the objective of modifying the rotor dynamic behavior, by means of proportional and derivative controllers.

\subsection{Active LEG Bearing as a calibrated actuator for non invasive system identification testing}

In general, the turbomachinery supported by tilting pad journal bearings does not possess self diagnosing capabilities, i.e. the ability to perform on-line dynamic testing of the supported rotor during its regular operation. This shortcoming arises from the lack of built-in components that are able to provide calibrated forces in a wide frequency range. Typically, this drawback is overcome by performing run-up/coast-down testing, where the residual unbalance is employed as the excitation source for in-situ characterization of the rotor dynamics. Such testing, although useful, requires to interrupt the machine normal operation regime.

The servovalve controlled LEG inlet flow enables the bearing to generate excitation forces over the rotor in a wide frequency range. Consequently, the Active LEG Bearing could be used to introduce self diagnosing capabilities to standard turbomachinery. The experimental results presented here exemplify this operation mode. The test rig was operated in configuration 2 . An electromagnetic shaker was used to excite the tilting arm vertical motion. The excitation force was measured using a piezoelectric load cell, and the resulting vertical movement was registered using displacement probes. By postprocessing these measurements, the frequency response function of the 
rotor movement versus the excitation force was obtained.

Afterwards, the same test was performed, but the excitation force exerted by the electromagnetic shaker was replaced by the active force generated in the bearing. For exciting the studied frequency range, $u_{V}$ was composed of a mean value of $0.25 \mathrm{~V}$, and a superimposed chirp signal of amplitude 0.1 $\mathrm{V}$, varying its frequency from $1 \mathrm{~Hz}$ to $200 \mathrm{~Hz}$ In this case, no direct measurement of the excitation force is available, hence the calibration functions already depicted in Figure 11 are used to determine the amount of force applied for each frequency and its phase lag with respect to the input signal. By using the previously determined calibration function, it is possible to obtain a frequency response function for the rotor response, and compare it with the benchmark result obtained with the electromagnetic shaker. See [21, 22] for details about the data processing method.

Figure 14 and 15 portray the results obtained for the frequency response function measured using the two excitation methods already discussed. It can be seen that the one obtained using the Active LEG Bearing as the excitation source can reproduce with good accuracy the benchmark results delivered by the electromagnetic shaker. The frequency response function obtained using the active bearing setup enables to track accurately the presence of the resonance located around $200 \mathrm{~Hz}$. Such resonance is particularly visible in the phase plot, locating the frequency value where the 90 degrees phase takes place. Concerning the amplitude of the frequency response function around the resonance area, results exhibit some deviation compared to the benchmark. It means that the active bearing excitation method would enable to locate natural frequencies with higher accuracy than their corresponding damping factors.

These results validate experimentally the idea of applying the proposed bearing design as a component able to introduce self-diagnosis capabilities in rotating machinery. For obtaining the reported results, some preliminary runs enabled to find the proper configuration for the servovalve input signal $u_{V}$. In this sense, the signal must enable to preserve the original system dynamics to comply with the "non invasive testing" requirement, and at the same time, to provide enough excitation force for achieving good coherence values in the frequency response function. These requirements were achieved by keeping the signal mean value equal for the electromagnetic shaker and the active bearing test, and by reducing the chirp amplitude to the minimum possible value that induced relevant active forces over the rotor, i.e. high coherence values for the obtained frequency response function. 


\subsection{Active $L E G$ Bearing as a calibrated actuator for closed loop active con- trol purposes}

Figure 12 and 13, presented in a previous section, portrayed the modification of the equivalent stiffness and damping coefficients for the studied Active LEG Bearing for different servovalve input signals $u_{V}$. From them, it was concluded that modifying the input signal in an open loop, constant valued, configuration induced negligible modification of the system dynamics. Figure 16 enables to observe this trend from the system dynamics perspective, in the form of the frequency response function of the vertical rotor movement. This result was obtained using the test rig in configuration 2, being the input the excitation force induced by the electromagnetic shaker and the ouput the rotor movement measured by the displacement probes. It can be seen that both the theoretical and the experimental value, exhibit a weak modification of the dynamic behavior when the servovalve input signal $u_{V}$ is set to two different constant values.

Due to the capabilites of the Active LEG Bearing in terms of generation of calibrated forces in a wide frequency range, the idea of introducing of a controller to synthetize the servovalve input signal as a function of the rotor vertical movement is explored here. For simplicity, and considering the scope of this article, only simple proportional and derivative controller are implemented for portraying the closed loop operation. In all cases, the control signal is superimposed to a constant value, in order to ensure that $u_{V}$ is always greater than zero and that no oil starvation takes place in the bearing. Mean value for $u_{V}$ is set to $1 \mathrm{~V}$, with the double objective of employing higher control gains (i.e. higher amplitude control signals), as well as studying the feasibility of operating the active bearing far from its $0 \mathrm{~V}$ set point. Since the LEG also provides the passive oil supply for the bearing operation, it is convenient to move as far away from the closed spool operation, in order to prevent oil starvation problems.

The experimental results are obtained using the same experimental setup applied for the results in Figure 16, with the only difference being the usage of a control unit to synthetize $u_{V}$ as a function of $y_{r}$ via proportional or derivative gains. On the other hand, theoretical results are obtained, where the frequency response function is calculated using the frequency reduced stiffness and damping coefficients delivered by the mathematical model, and assuming that the tilting arm - rotor arrangement behaves like a rigid body pivoted in one end with equivalent inertia $I$ : 


$$
F R F(\omega)=\frac{\left(\frac{l_{2}}{l_{1}}\right)^{2}}{k_{A L E G}(\omega)+i \omega d_{A L E G}(\omega)-\omega^{2} \frac{I}{l_{1}^{2}}}
$$

Figure 17, 18, 19, 20 depict the frequency response function obtained for different operational conditions, when proportional and derivative controllers are established, superimposing the control signal to a mean value of $1 \mathrm{~V}$. In general, it can be seen that the introduction of the controllers entail a stronger modification of the original system dynamics (represented in each plot by the open loop operation with a constant voltage of $1 \mathrm{~V}$ ). Depending on the value of the gains, it becomes possible to affect the amplitude of the frequency response function, increasing or diminishing its magnitude as a function of frequency. The influence of the closed loop control becomes stronger in the lower frequency range, due to the limitations of the Active LEG Bearing in terms the magnitude of its active force for higher frequencies. Furthermore, it can be appreciated that the effect of the closed loop operation becomes weaker for higher applied load on the bearing, being in such cases the oil film pressure field dominant over the forces generated by the controllable LEG inlet flow, as discussed previously in this article.

Regarding the comparison between theory and experiment, the reported results exhibit good correspondence between them. The observed deviations arise from additional dynamics existing in the experimental setup, which can not be captured by the theoretical results obtained by considering only rigid body movement for the tilting arm arrangement.

Although no optimization has been performed for the value of the proportional and derivative gains, the presented results are sufficient to demonstrate the ability of the Active LEG Bearing to affect the system dynamics over a wide frequency range, via closed loop operation. Noteworthy is that these results were obtained with mean value of $1 \mathrm{~V}$ for $u_{V}$, away from the usual linearization point for a servovalve arrangement. Furthermore, they enable to verify the soundness of the implemented mathematical model, enabling to predict the dynamic behavior of a rigid rotor supported by an Actively Lubricated LEG Tilting Pad Bearing under open and closed loop operation.

\section{CONCLUSION AND FUTURE ASPECTS}

This article constitutes the second step in a research effort aiming at evaluating the feasibility of introducing active characteristics into standard leading 
edge groove (LEG) tilting pad journal bearings. By means of theoretical and experimental results, it has been proven that the servovalve controlled LEG inlet flow is a viable alternative to transform a tilting pad bearing into a calibrated actuator, able to generate controllable forces in a wide frequency range. Consequently, by combining several of these active LEG pads in a full bearing, a mechatronic machine element could be obtained, able to introduce smart characteristics to the machine supported by it.

The experimental results presented here proved that the proposed Active LEG Tilting Pad design is able to modify its steady state and dynamic properties depending on an electrical signal fed into a high-response servovalve. Two possible operations modes were experimentally tested, foreseeing possible industrial applications of this concept. As such, it was proved that the studied system could be used as the actuator for in-situ dynamic testing of rotating machinery. Furthermore, the introduction of closed loop control strategies for synthetizing the servovalve input signal enabled to modify the dynamic behavior of a rigid rotor supported by the proposed active bearing setup.

The comparison between theory and experiment enabled to validate the mathematical model for the Actively Lubricated LEG Tilting Pad. In general, good agreement with experimental data was obtained. It was noted that the coefficients for the linearized model of the LEG hydraulic supply system area particularly relevant for obtaining such agreement, yielding some additional work in the experimental sense related to the obtention of such coefficients.

Considering the promising results obtained in this work, the next step in this research effort will be to test the proposed active bearing design in a setup that resembles in closer way the application of this concept (flexible rotor supported by LEG Tilting Pad Bearings featuring the actively lubricated LEG concept).

\section{ACKNOWLEDGMENTS}

This work has been financed by CONICYT Chile, project FONDECYT Iniciacion No. 11150112

\section{References}

[1] J. M. Vance, Rotordynamics of Turbomachinery, John Wiley \& Sons, 1988. 
[2] D. W. Childs, Turbomachinery Rotordynamics: Phenomena, Modeling, and Analysis, John Wiley \& Sons, 1993.

[3] R. Lanes, R. Flack, D. Lewis, Experiments on the Stability and Response of a Flexible Rotor in Three Types of Journal Bearings, ASLE Transactions 25 (1982) 289-298.

[4] H. Ulbrich, J. Althaus, Actuator Design for Rotor Control, ASME Design Technical Conference: Proceedings of the 12th Bienial Conference on Mechanical Vibration and Noise (1989) 17-22.

[5] D. C. Deckler, R. J. Veillette, M. J. Braun, F. K. Choy, Simulation and Control of an Active Tilting-Pad Journal Bearing, Tribology Transactions 47 (2004) 440-458.

[6] A. Wu, M. De Queiroz, A New Active Tilting-Pad Bearing: Non Linear Modeling and Feedback Control, STLE Tribology Transactions 53 (2010) 755-763.

[7] A. Wu, Z. Cai, M. De Queiroz, Model-Based Control of Active TiltingPad Bearings, Mechatronics, IEEE/ASME Transactions 12 (2007) 689695.

[8] H. Viveros, R. Nicoletti, Lateral Vibration Attenuation of Shafts Supported by Tilting-Pad Journal Bearing with Embedded Electromagnetic Actuators, ASME Journal of Engineering for Gas Turbines and Power 136 (2014) 042503.

[9] I. F. Santos, Design and Evaluation of Two Types of Active Tilting Pad Journal Bearings, The Active Control of Vibration (1994) 79-87.

[10] I. F. Santos, F. H. Russo, Tilting-Pad Journal Bearings with Electronic Radial Oil Injection, ASME Journal of Tribology 120 (1998) 583-594.

[11] I. F. Santos, R. Nicoletti, THD Analysis in Tilting-Pad Journal Bearings using Multiple Orifice Hybrid Lubrication, ASME Journal of Tribology 121 (1999) 892-900.

[12] A. M. Haugaard, I. F. Santos, Multi-Orifice Active Tilting-Pad Journal Bearings-Harnessing of Synergetic Coupling Effects, Tribology International 43 (2010) 1374-1391. 
[13] A. Cerda, B. B. Nielsen, I. F. Santos, Steady State Characteristics of a Tilting Pad Journal Bearing with Controllable Lubrication: Comparison Between Theoretical and Experimental Results, Tribology International 58 (2013) 85-97.

[14] J. Salazar, I. F. Santos, Active Tilting Pad Journal Bearings Supporting Flexible Rotors: Part II -the Model Based Feedback Controlled Lubrication, Tribology International 107 (2017) 106-115.

[15] I. F. Santos, P. Svendsen, Non Invasive Parameter Identification in Rotordynamics via Fluid Film Bearings - Linking Active Lubrication and Operational Modal Analysis, ASME Journal of Engineering for Gas Turbines and Power 139 (2017) 062507.

[16] A. C. Varela, A. B. García, I. F. Santos, Modelling of LEG Tilting Pad Journal Bearings with Active Lubrication, Tribology International 107 (2017) 250-263.

[17] W. Dmochowski, K. Brockwell, S. DeCamillo, A. Mikula, A Study of the Thermal Characteristics of the Leading Edge Groove and Conventional Tilting Pad Journal Bearings, ASME Journal of Tribology 115 (1993) 219-226.

[18] S. Edney, G. Heitland, S. DeCamillo, Testing, Analysis, and CFD Modeling of a Profiled Leading Edge Groove Tilting Pad Journal Bearing, in: Proceedings of ASME Turbo Expo 1998, 1998, pp. 2-5.

[19] K. Ikeda, T. Hirano, T. Yamashita, M. Mikami, H. Sakakida, An Experimental Study of Static and Dynamic Characteristics of a $580 \mathrm{~mm}(22.8$ in) Diameter Direct Lubrication Tilting Pad Journal Bearing, ASME Journal of Tribology 128 (2006) 146-154.

[20] K. Bang, J. Kim, Y. Cho, Comparison of Power Loss and Pad Temperature for Leading Edge Groove Tilting Pad Journal Bearings and Conventional Tilting Pad Journal Bearings, Tribology International 43 (2010) 1287-1293.

[21] I. F. Santos, A. Cerda, Actively Lubricated Bearings Applied as Calibrated Shakers to Aid Parameter Identification in Rotordynamics, Proceedings of ASME Turbo Expo 2013 (2013). 
[22] A. Cerda, I. F. Santos, Tilting-Pad Journal Bearings with Active Lubrication Applied as Calibrated Shakers: Theory and Experiment, ASME Journal of Vibrations and Acoustics 136 (2014).

[23] A. C. Varela, I. F. Santos, Dynamic Coefficients of a Tilting Pad with Active Lubrication: Comparison Between Theoretical and Experimental Results, ASME Journal of Tribology 137 (2015) 031704.

[24] J. E. Gaines, D. W. Childs, The Impact of Pad Flexibility on the Rotordynamic Coefficients of Tilting-Pad Journal Bearings, ASME Journal of Engineering for Gas Turbines and Power 138 (2016) 082501. 
a) Steady State Results, 1000 RPM
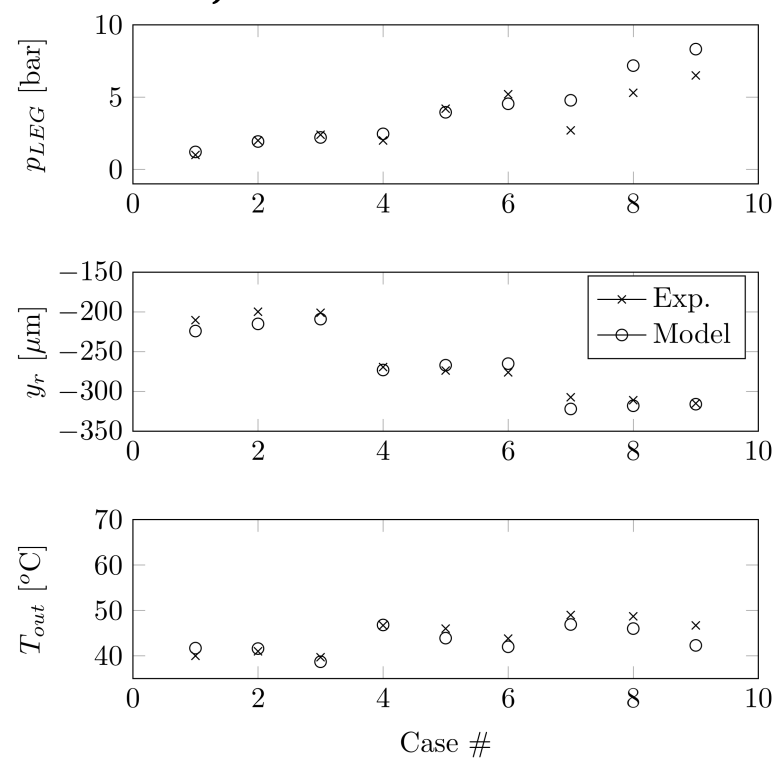

b) Steady State Results, 2000 RPM
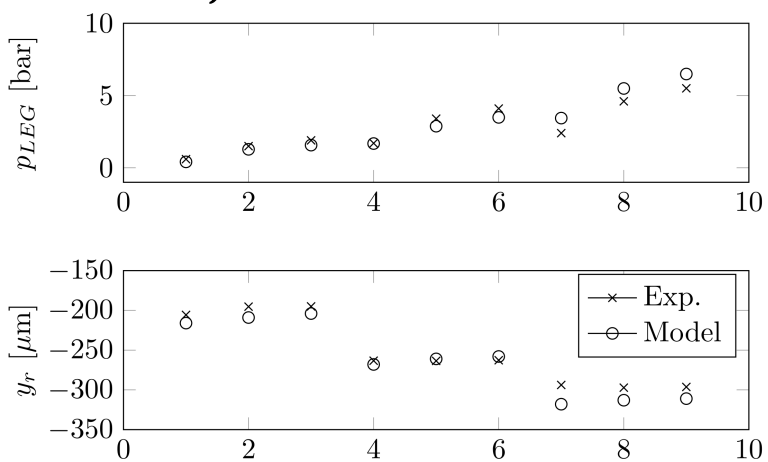

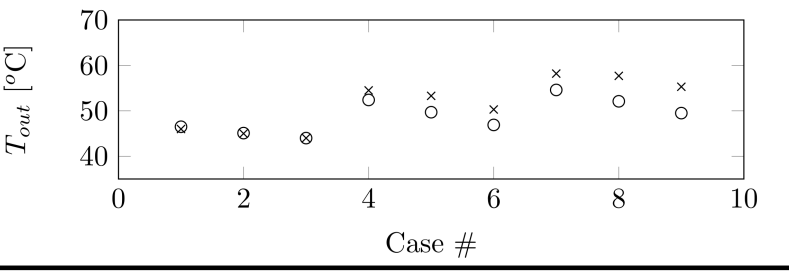

C) Steady State Results, 3000 RPM
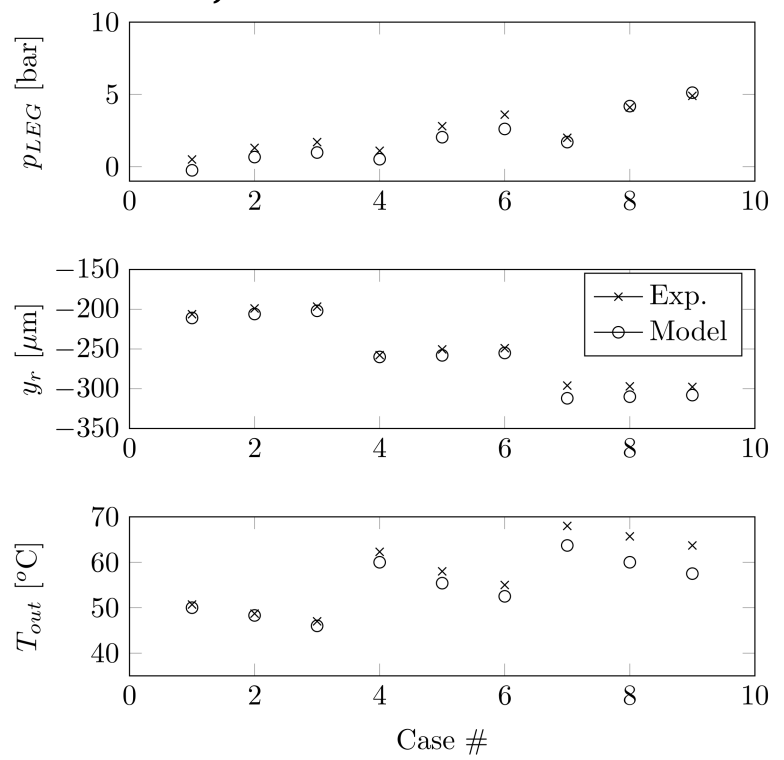

Figure 7: Steady state characterization: comparison of experimental and model results for the different test cases defined in Table 2. The journal rotational speed is set to 1000 RPM (a), 2000 RPM (b), 3000 RPM (c) respectively. 
Rotor Vertical Force, 1000 RPM

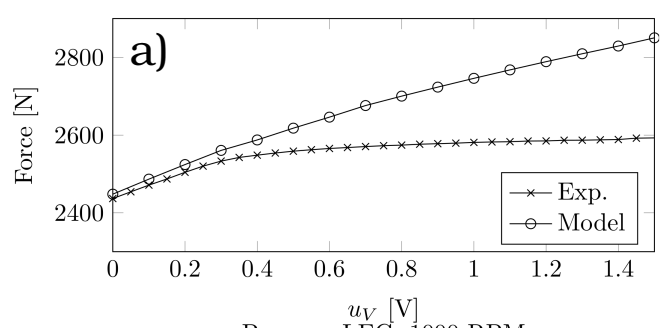

Pressure LEG, 1000 RPM

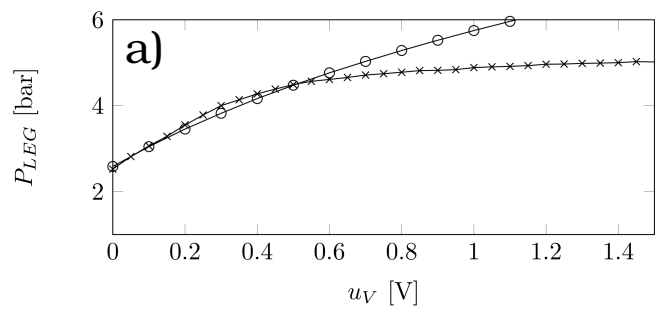

Rotor Vertical Force , 1000 RPM

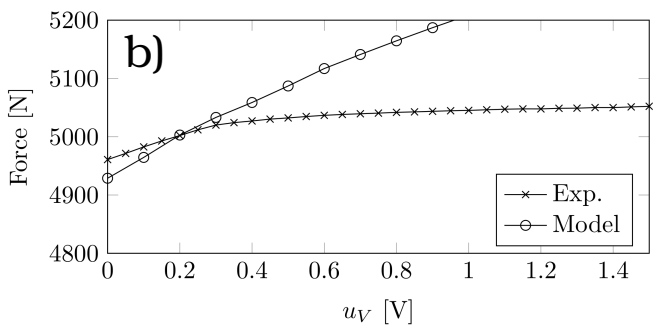

Pressure LEG, 1000 RPM

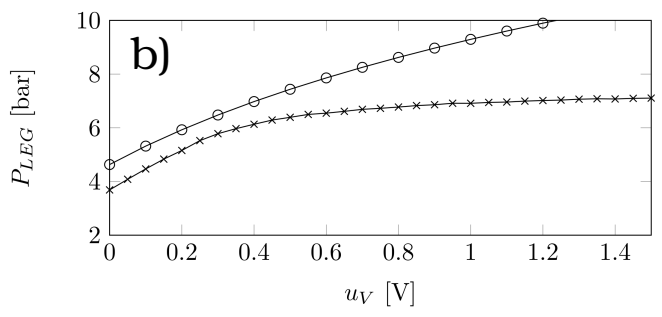

Figure 8: Active LEG bearing calibration function: comparison of experimental and model results for the quasistatic characterization of the bearing active force and LEG pressure. The journal rotational speed is set to $1000 \mathrm{RPM}$, and the bearing mean load is set to 1000 $\mathrm{N}$ (a) and $5000 \mathrm{~N}$ (b) respectively. 
Rotor Vertical Force, 3000 RPM

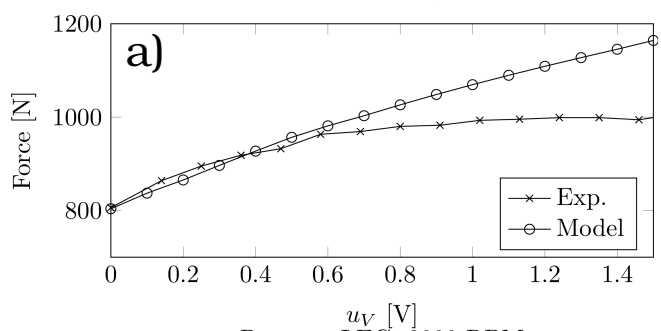

Pressure LEG, 3000 RPM

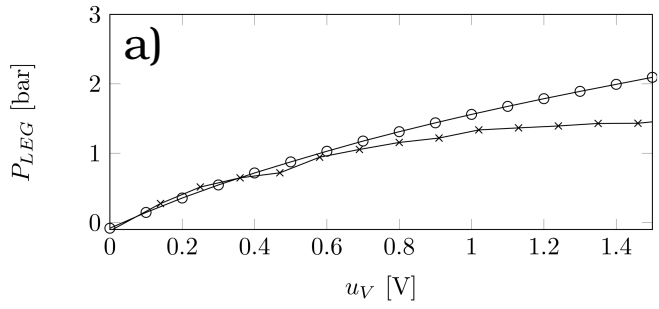

Rotor Vertical Force , 3000 RPM

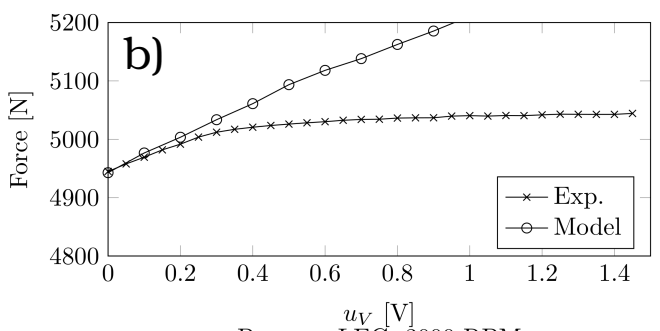

Pressure LEG, 3000 RPM

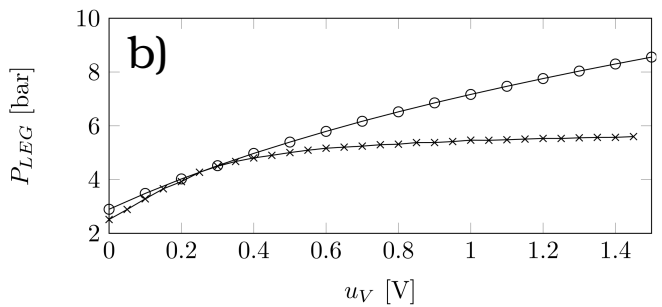

Figure 9: Active LEG bearing calibration function: comparison of experimental and model results for the quasistatic characterization of the bearing active force and LEG pressure. The journal rotational speed is set to 3000 RPM, and the bearing mean load is set to 1000 $\mathrm{N}$ (a) and $5000 \mathrm{~N}$ (b) respectively. 
Comparison Transfer Functions Servovalve Input Signal: 1000 RPM, 5000 N
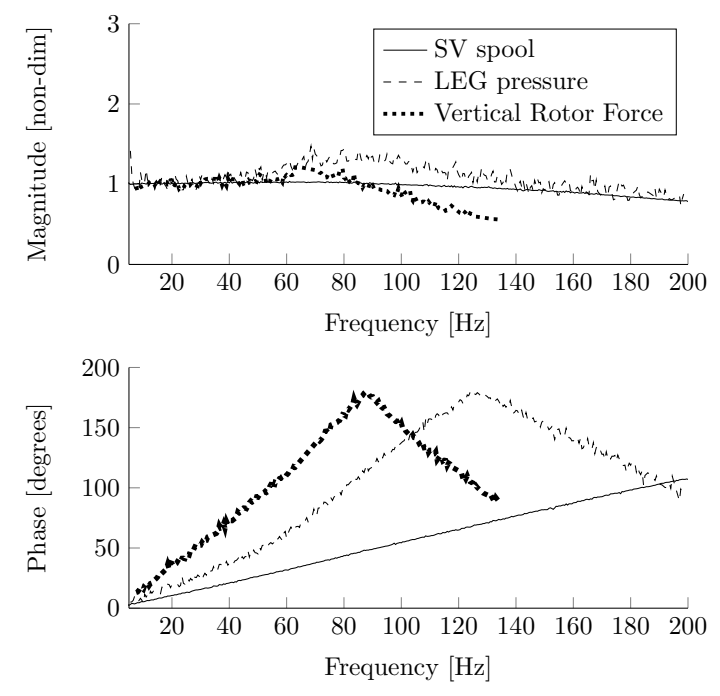

Figure 10: Comparison of the experimentally obtained transfer functions of the servovalve spool movement, the LEG pressure, and bearing active force versus the input signal $u_{V}$ sent to the servovalve. The magnitude of the transfer functions has been normalized for comparison purposes. The journal rotational speed is set to 1000 RPM, and the bearing mean load is set to $5000 \mathrm{~N}$. 

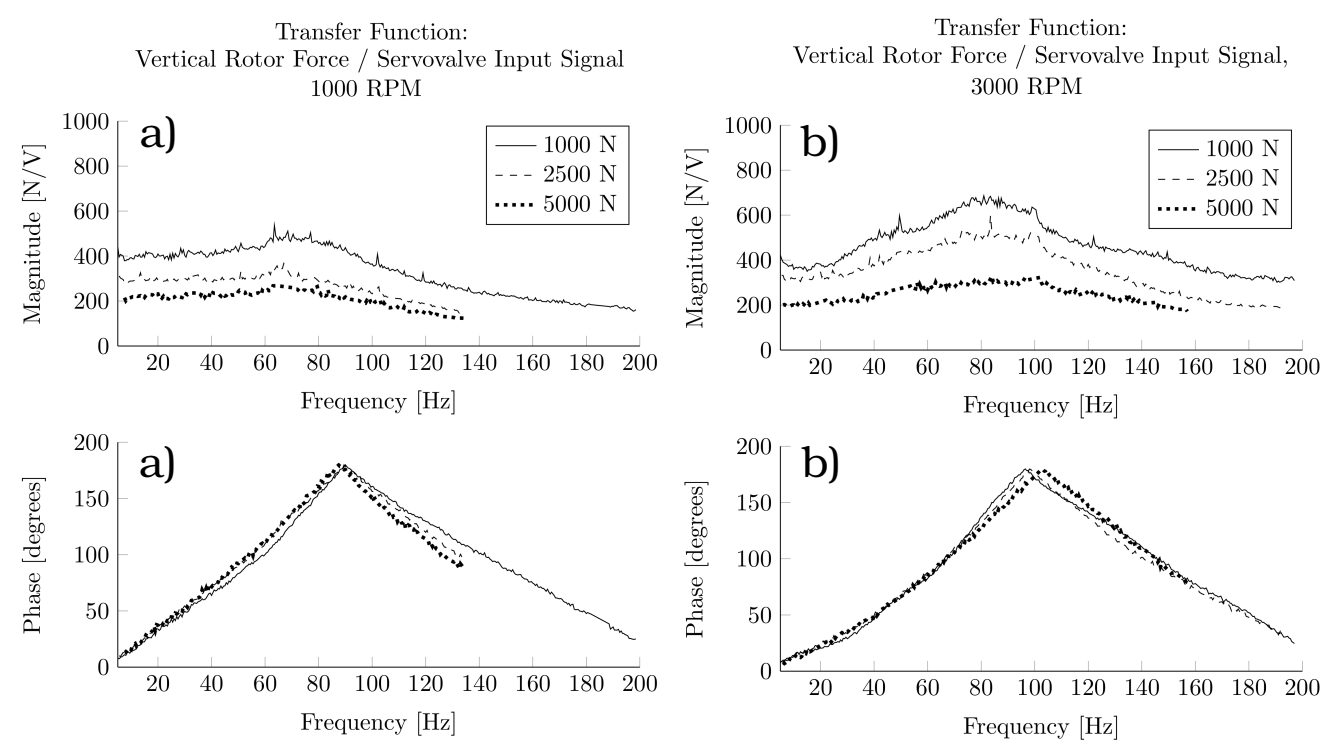

Figure 11: Active LEG bearing calibration function: experimental results for the dynamic characterization of the bearing active force. The journal rotational speed is set to 1000 RPM (a) and 3000 RPM (b), and the bearing mean load is set to three diferent values. 

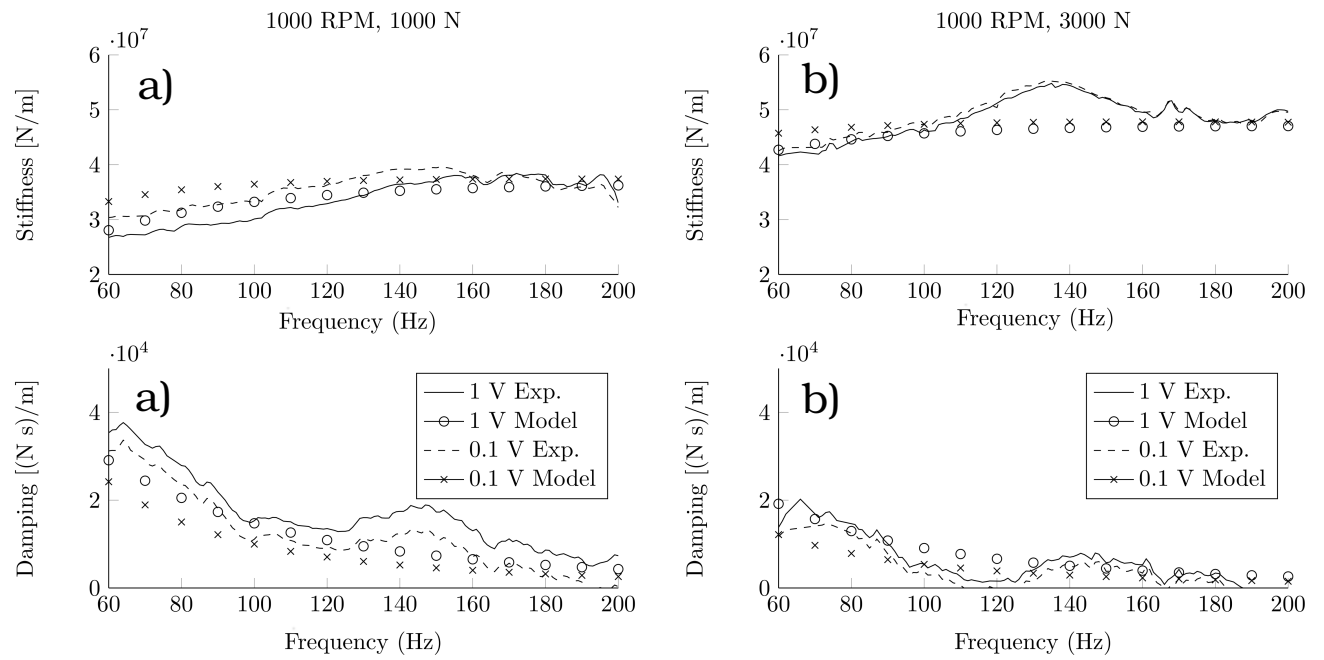

Figure 12: Equivalent stiffness $k_{A L E G}$ and damping $d_{A L E G}$ coefficients of the Active LEG tilting pad bearing: experimental and theoretical results. The journal rotational speed is set to $1000 \mathrm{RPM}$, and the bearing applied load is set to $1000 \mathrm{~N}$ (a) and $3000 \mathrm{~N}$ (b). Two different voltage values are fed into the servovalve. 

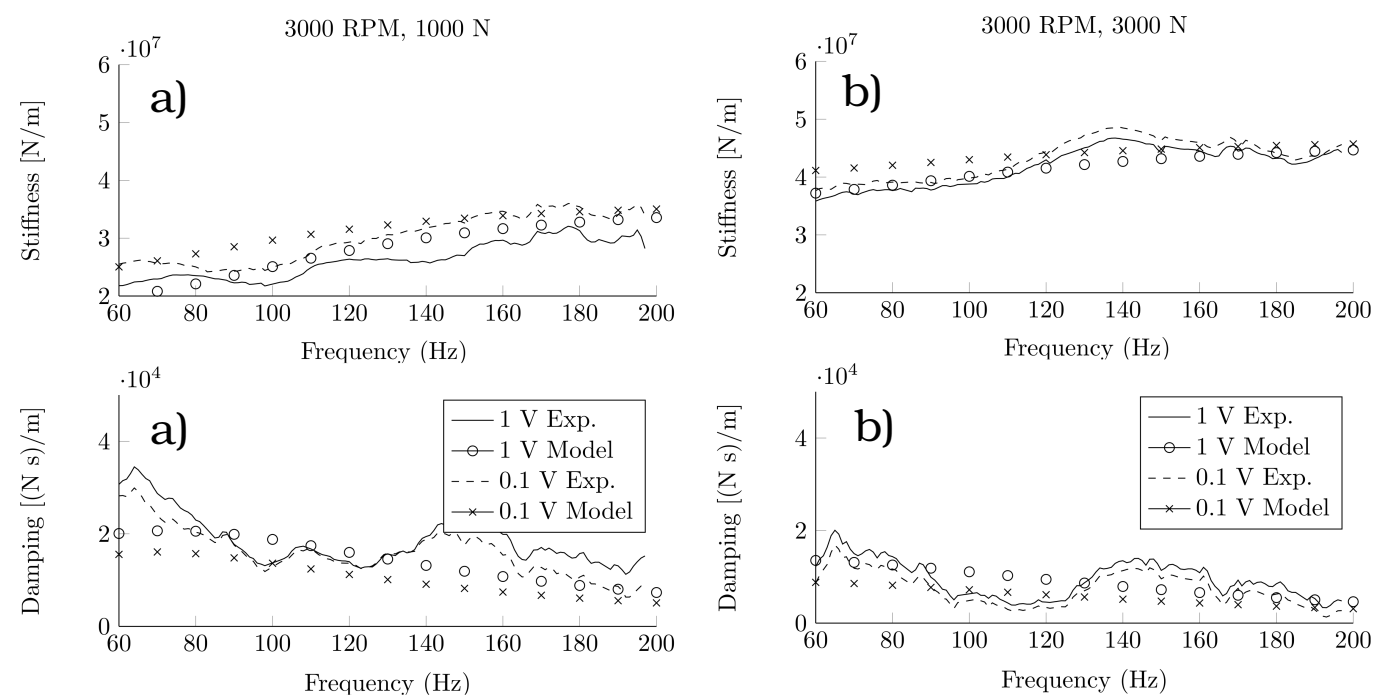

Figure 13: Equivalent stiffness $k_{A L E G}$ and damping $d_{A L E G}$ coefficients of the Active LEG tilting pad bearing: experimental and theoretical results. The journal rotational speed is set to $3000 \mathrm{RPM}$, and the bearing applied load is set to $1000 \mathrm{~N}$ (a) and $3000 \mathrm{~N}$ (b). Two different voltage values are fed into the servovalve. 

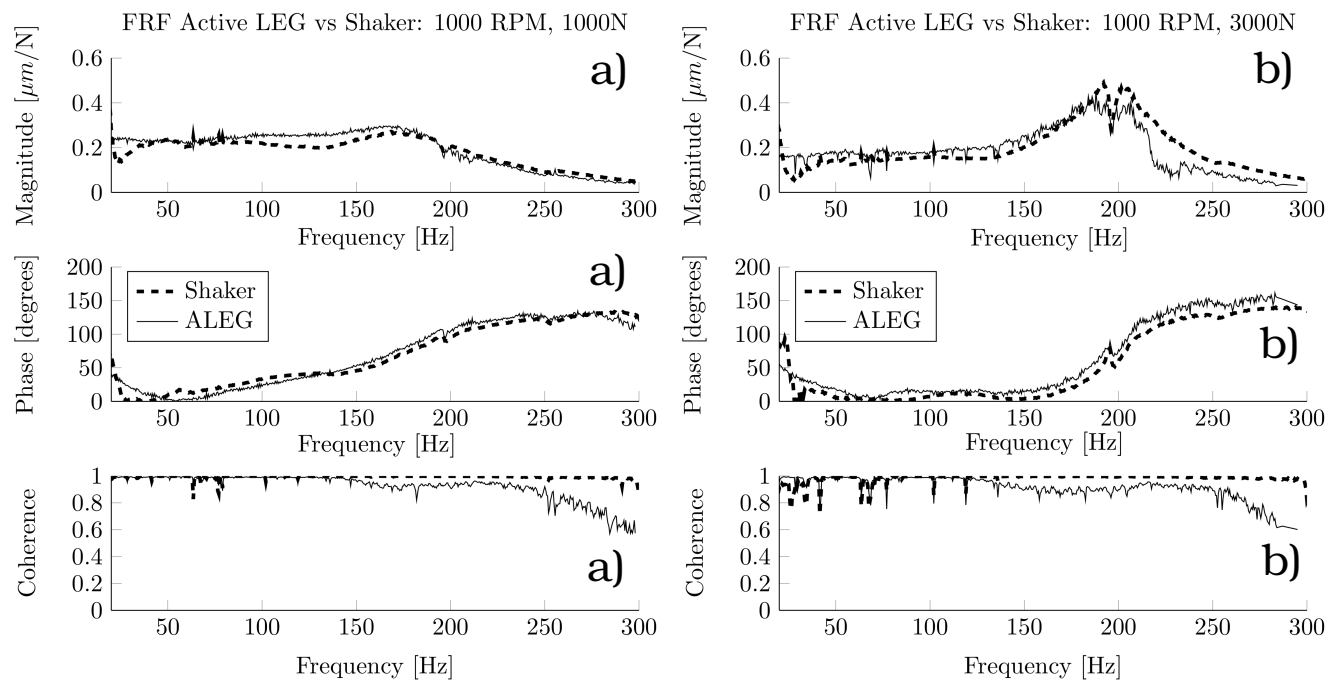

Figure 14: Active LEG Bearing operating as a calibrated actuator: comparison of the frequency response function for the vertical rotor movement obtained using an electromagnetic shaker and the Active LEG bearing as excitation sources. The journal rotational speed is set to $1000 \mathrm{RPM}$, and the bearing applied load is set to $1000 \mathrm{~N}$ (a) and $3000 \mathrm{~N}$ (b). 

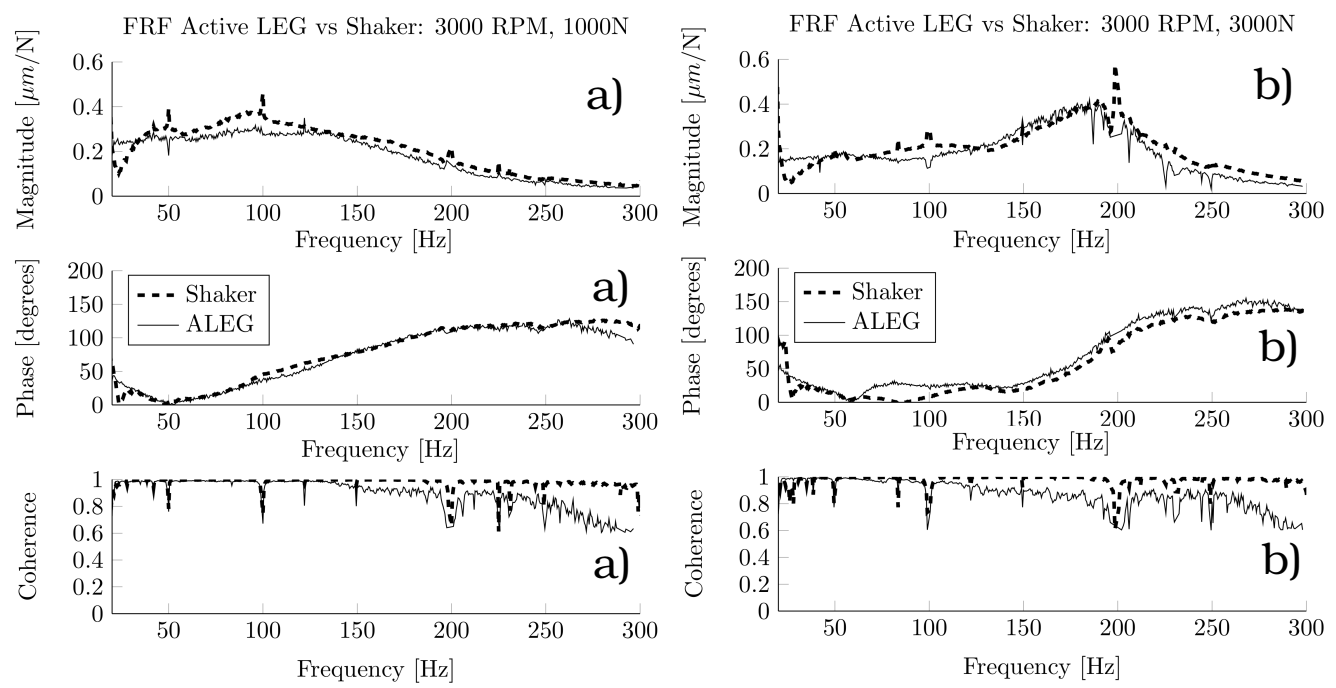

Figure 15: Active LEG Bearing operating as a calibrated actuator: comparison of the frequency response function for the vertical rotor movement obtained using an electromagnetic shaker and the Active LEG bearing as excitation sources. The journal rotational speed is set to $3000 \mathrm{RPM}$, and the bearing applied load is set to $1000 \mathrm{~N}$ (a) and $3000 \mathrm{~N}$ (b). 
FRF Experiment

FRF Model
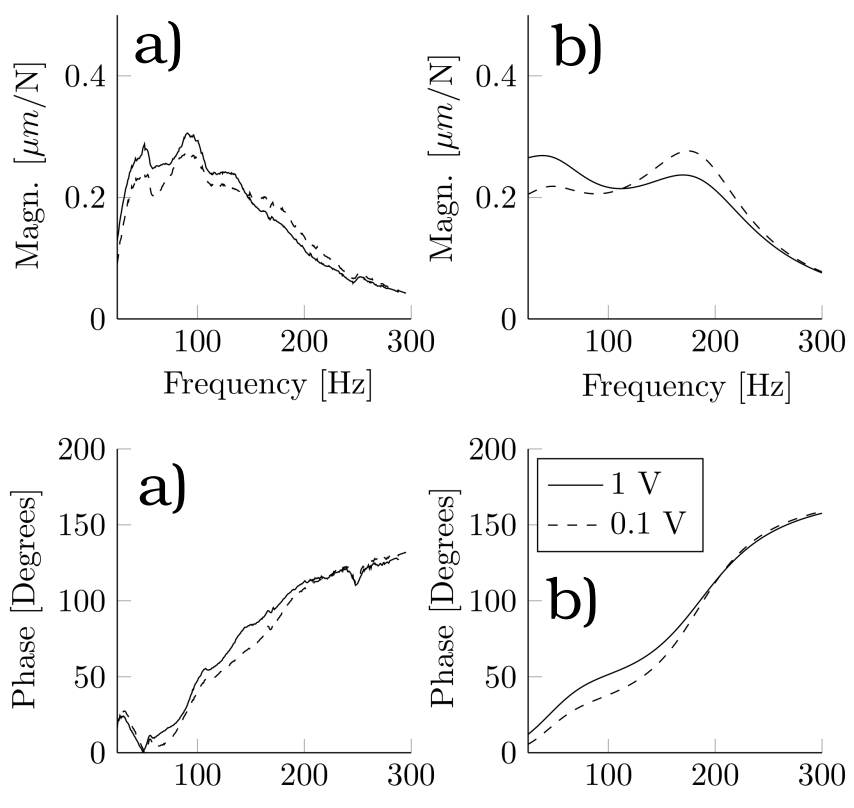

Frequency $[\mathrm{Hz}]$

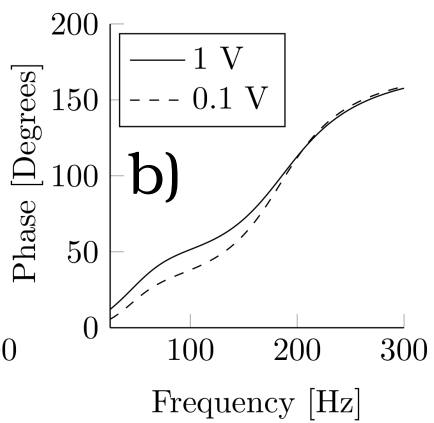

Figure 16: Frequency Response Functions for the rotor vertical movement: experimental and theoretical results for open loop operation. The journal rotational speed is set to 3000 RPM, and the bearing applied load is set to $1000 \mathrm{~N}$. Two different voltage values are fed into the servovalve. 
FRF Experiment

FRF Model
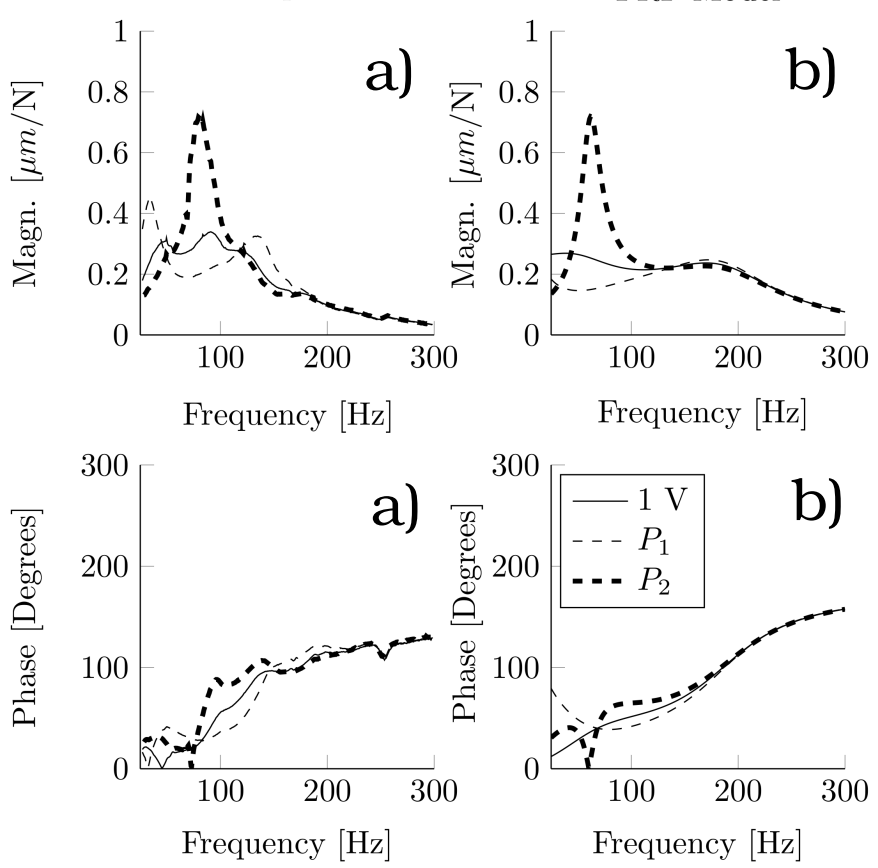

Figure 17: Frequency Response Functions for the rotor vertical movement: experimental and theoretical results for closed loop proportional control operation. The journal rotational speed is set to 3000 RPM and the bearing applied load is set to $1000 \mathrm{~N}$. Results for open loop operation are provided for comparison. The proportional gains are set to $P_{1}=50000[\mathrm{~V} / \mathrm{m}]$ and $P_{2}=-P_{1}$ 

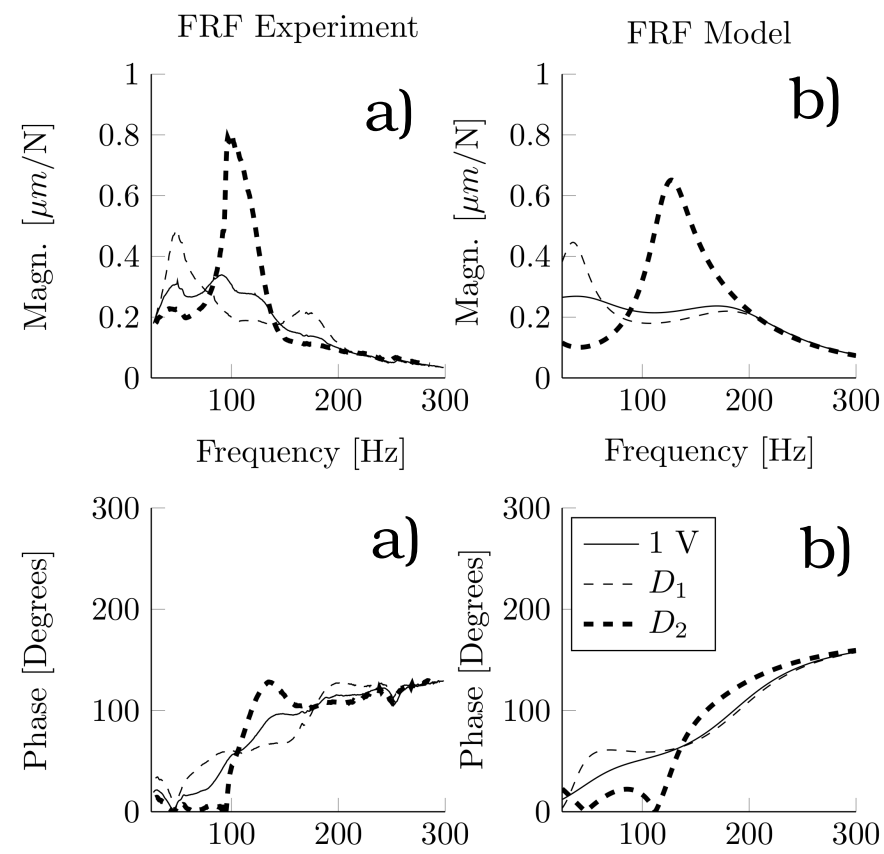

Frequency $[\mathrm{Hz}]$

Frequency $[\mathrm{Hz}]$

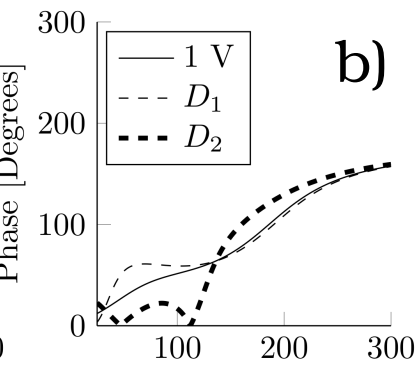

Frequency $[\mathrm{Hz}]$

Figure 18: Frequency Response Functions for the rotor vertical movement: experimental (a) and theoretical (b) results for closed loop derivative control operation. The journal rotational speed is set to $3000 \mathrm{RPM}$ and the bearing applied load is set to $1000 \mathrm{~N}$. Results for open loop operation are provided for comparison. The derivative gains are set to $D_{1}=100[\mathrm{~s} V / \mathrm{m}]$ and $D_{2}=-D_{1}$ 
FRF Experiment

FRF Model
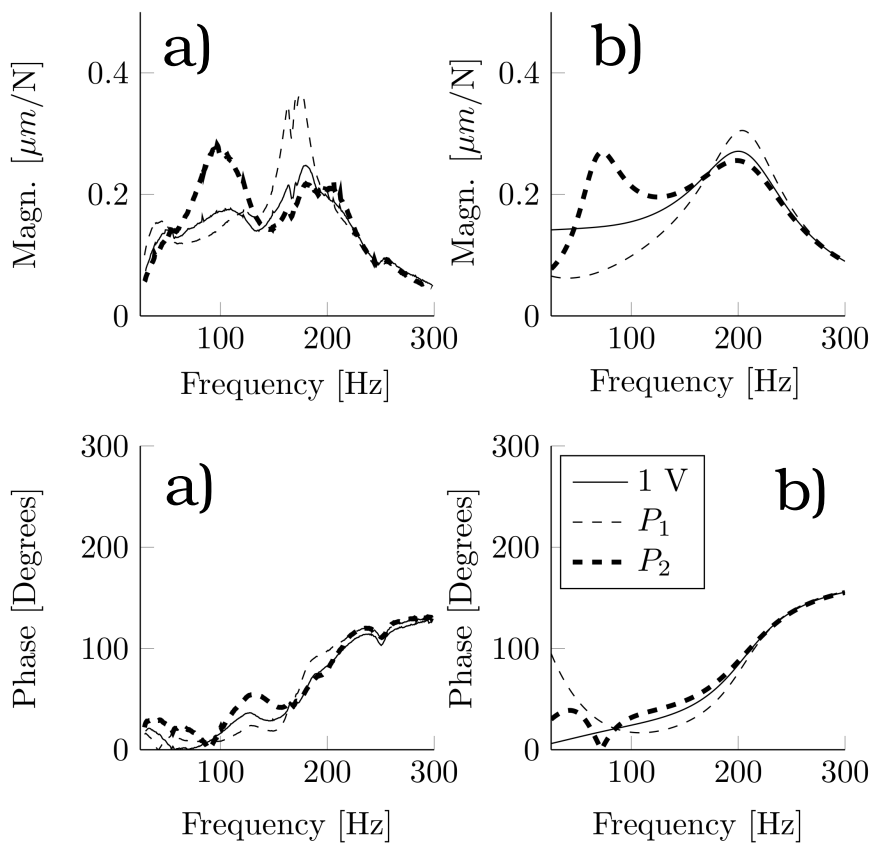

Figure 19: Frequency Response Functions for the rotor vertical movement: experimental (a) and theoretical (b) results for closed loop proportional control operation. The journal rotational speed is set to $3000 \mathrm{RPM}$ and the bearing applied load is set to $3000 \mathrm{~N}$. Results for open loop operation are provided for comparison. The proportional gains are set to $P_{1}=50000[\mathrm{~V} / \mathrm{m}]$ and $P_{2}=-P_{1}$ 
FRF Experiment
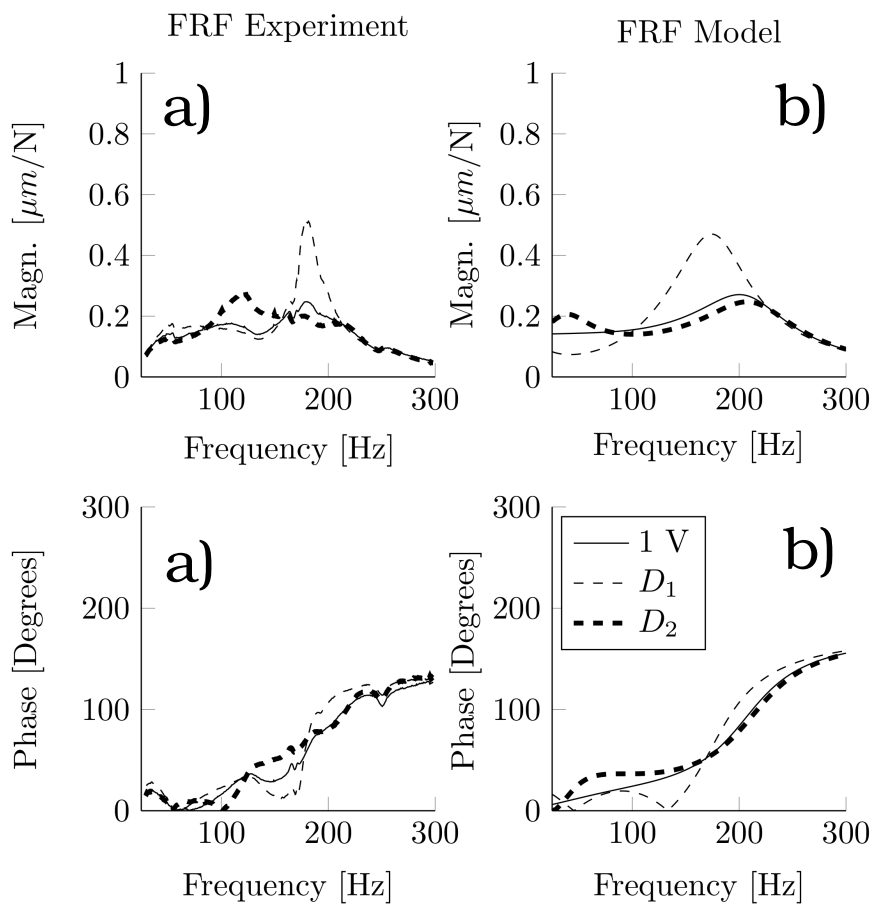

Figure 20: Frequency Response Functions for the rotor vertical movement: experimental (a) and theoretical (b) results for closed loop derivative control operation. The journal rotational speed is set to $3000 \mathrm{RPM}$ and the bearing applied load is set to $3000 \mathrm{~N}$. Results for open loop operation are provided for comparison. The derivative gains are set to $D_{1}=$ $100[\mathrm{sV} / \mathrm{m}]$ and $D_{2}=-D_{1}$ 